\title{
Checkpoint suppressor 1 suppresses transcriptional activity of ERa and breast cancer cell proliferation via deacetylase SIRT1
}

Zhaowei Xu', Yangyang Yang ${ }^{1}$, Bowen $\mathrm{Li}^{1}$, Yanan Li', Kangkai Xia', Yuxi Yang ${ }^{1}$, Xiahui Li', Miao Wang ${ }^{1}$, Shujing $\mathrm{Li}^{1}$ and Huijian $\mathrm{Wu}^{1}$

\begin{abstract}
Breast cancer is a highly heterogeneous carcinoma in women worldwide, but the underlying mechanisms that account for breast cancer initiation and development have not been fully established. Mounting evidence indicates that Checkpoint suppressor 1 (CHES1) is tightly associated with tumorigenesis and prognosis in many types of cancer. However, the definitive function of CHES1 in breast cancer remains to be explored. Here we showed that CHES1 had a physical interaction with estrogen receptor-a (ERa) and repressed the transactivation of ERa in breast cancer cells. Mechanistically, the interaction between CHES1 and ERa enhanced the recruitment of nicotinamide adenine dinucleotide (NAD+) deacetylase Sirtuin 1 (SIRT1), and it further induced SIRT1-mediated ERa deacetylation and repression on the promoter-binding enrichment of ERa. In addition, we also found that the expression of CHES1 was repressed by estrogen-ERa signaling and the expression level of CHES1 was significantly downregulated in ERapositive breast cancer. The detailed mechanism was that ERa may directly bind to CHES1 potential promoter via recognizing the conserved estrogen response element (ERE) motif in response to estrogen stimulation. Functionally, CHES1 inhibited ERa-mediated proliferation and tumorigenesis of breast cancer cells in vivo and in vitro. Totally, these results identified a negative cross-regulatory loop between ERa and CHES1 that was required for growth of breast cancer cells, it might uncover novel insight into molecular mechanism of CHES1 involved in breast cancer and provide new avenues for molecular-targeted therapy in hormone-regulated breast cancer.
\end{abstract}

\section{Introduction}

Estrogen signaling pathway is aberrantly active in hormone-responsive breast cancer, which has a vital role in the initiation and development of breast carcinoma ${ }^{1,2}$. Estrogen receptor- $\alpha(E R \alpha)$, a member of nuclear receptor superfamily, serves as a key factor to regulate $E_{2}$ response and signaling transduction ${ }^{3,4}$. In addition, it can promote estrogen-dependent cancer progression via regulating the

\footnotetext{
Correspondence: Huijian Wu (wuhj@dlut.edu.cn)

${ }^{1}$ School of Life Science and Biotechnology, Dalian University of Technology, Dalian, China

These authors contributed equally: Zhaowei Xu, Yangyang Yang

Edited by J. Chipuk
}

transcription of genes linked to cell proliferation and survival $^{5,6}$. ER $\alpha$ exhibits transcriptional activation or repression via recruiting co-activators or co-repressors to the promoters or enhancers of target genes, and the definitive function of ER $\alpha$ in transcriptional regulation is largely decided by its co-regulators in certain cellular context ${ }^{7,8}$. Although a large number of co-regulators of $E R \alpha$ have been identified, the integrated interaction network of ER $\alpha$ remains to be explored. Moreover, the function of ER $\alpha$ is also tightly associated with posttranslational modifications such as ubiquitination ${ }^{2,9}$, methylation $^{10}$, phosphorylation ${ }^{11}$, acetylation ${ }^{12,13}$, and

\section{(c) The Author(s) 2018}

(c) Open Access This article is licensed under a Creative Commons Attribution 4.0 International License, which permits use, sharing, adaptation, distribution and reproduction in any medium or format, as long as you give appropriate credit to the original author(s) and the source, provide a link to the Creative Commons license, and indicate if changes were made. The images or other third party material in this article are included in the article's Creative Commons license, unless indicated otherwise in a credit line to the material. If material is not included in the article's Creative Commons license and your intended use is not permitted by statutory regulation or exceeds the permitted use, you will need to obtain permission directly from the copyright holder. To view a copy of this license, visit http://creativecommons.org/licenses/by/4.0/. 


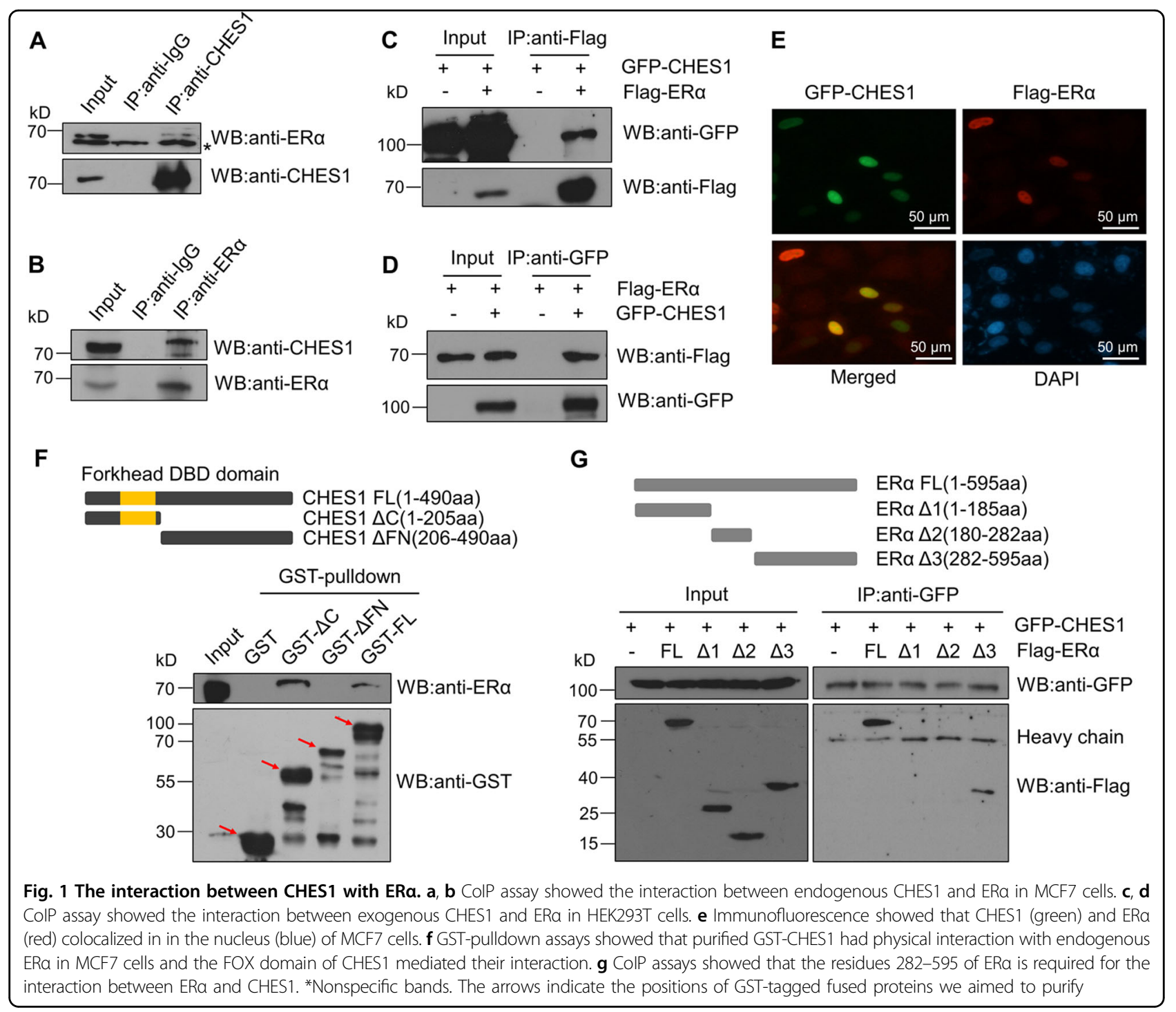

sumoylation $^{14,15}$. Among these modifications, p300mediated acetylation of ER $\alpha$ facilitates the $E_{2}$-responsive DNA-binding ability and promotes its transcriptional activity $^{12}$. Furthermore, ER $\alpha$ deacetylation is achieved by native cellular histone deacetylases (HDACs), such as Trichostatin A-sensitive enzymes (Class I and II HDACs) and nicotinamide-sensitive enzymes (Class III HDACs) ${ }^{13}$. Sirtuin 1 (SIRT1)-mediated deacetylation of ER $\alpha$ results in a repressive effect on ER $\alpha$ transactivation, which has a vital role in the progression of ER $\alpha$-positive breast cancer $^{16}$.

Forkhead box (FOX) proteins are a large transcriptional family which contains an evolutionary conserved forkhead or winged-helix DNA-binding domain ${ }^{17}$. They were identified in Drosophila melanogaster first ${ }^{18}$. In addition, there are more than 50 members found in human proteome and they are further categorized into 19 subgroups $^{18}$. Despite studies that confirmed FOX proteins serve as key factors in embryogenesis, metabolism, and tumorigenesis, the molecular functions of FOX family members are divergent and even opposing ${ }^{19,20}$. Therefore, it warrants further investigation to explore the defined function of a certain FOX protein in different physiological processes. CHES1 (also named FOXN3) belongs to FOXN subgroup and contains a conserved FOX domain in $\mathrm{N}$-terminal; it has a significant role in various processes including DNA damage ${ }^{21,22}$, cell cycle arrest ${ }^{23,24}$, and the development of organs ${ }^{19,25}$. In addition, CHES1 may act as a transcriptional repressor via interacting with SIN3A/HDACs complex ${ }^{19,20,25}$ or other coregulators such as $\mathrm{SKIP}^{26}, \mathrm{Menin}^{22}$, and $\beta$-catenin ${ }^{27}$. A growing number of studies imply that CHES1 is tightly associated with tumor initiation and progression, and it is dysregulated in many types of carcinoma such as oral squamous cell carcinoma ${ }^{28}$, ovarian cancer $^{29}$, colorectal cancer $^{27,30}$, glioblastoma ${ }^{31}$, and hepatocellular carcinoma ${ }^{32}$. These studies have demonstrated that CHES1 had a weaker 
expression level in tumor tissues and its lower expression implied a poor prognosis ${ }^{31}$. Studies also show that CHES1 can inhibit protein biosynthesis ${ }^{33}$ or the transcriptional expression of oncogenes such as $E 2 F 5^{32}, c-M Y C^{34}$, and $\mathrm{CDH} 2^{30}$. However, the defined function of CHES1 in breast cancer is still elusive. A recent study indicates that CHES1 may have a role in progress of metastasis and invasion in hormone-responsive breast carcinoma ${ }^{20}$, but more biological functions of CHES1 involved in breast cancer remain to be explored.

Herein, we identified the association between CHES1 and ER $\alpha$ in breast cancer cells; further investigation revealed that a negative regulatory loop between CHES1 and ER $\alpha$ existed in breast cancer, and this regulatory model modulated the signaling transduction of $E_{2}$-ER $\alpha$ and had a role in progress and prognosis of breast cancer.

\section{Results}

\section{CHES1 has physical interaction with ERa}

As described previously, the other member of FOX protein family, FOXA1 ${ }^{35}$, FOXO3a ${ }^{36}$, and FOXK2 $2^{37,38}$, can modulate the activity of nuclear receptors via proteins physical interaction; here we speculated that CHES1, also known as FOXN3, may regulate ER $\alpha$ activity through the interaction with $\mathrm{ER} \alpha$ in breast cancer cells. To confirm this possibility, we performed co-immunoprecipitation (CoIP) assay in MCF7 (Fig. 1a,b) and HEK293T cells (Fig. 1c,d). The results detected the existence of interaction between endogenous and exogenous CHES1 with $E R \alpha$. To further support this assumption, immunofluorescence and (GST)-pulldown assays were conducted. The results showed that both GFP-CHES1 and Flag-ER $\alpha$ were located in the nucleus and an evident association

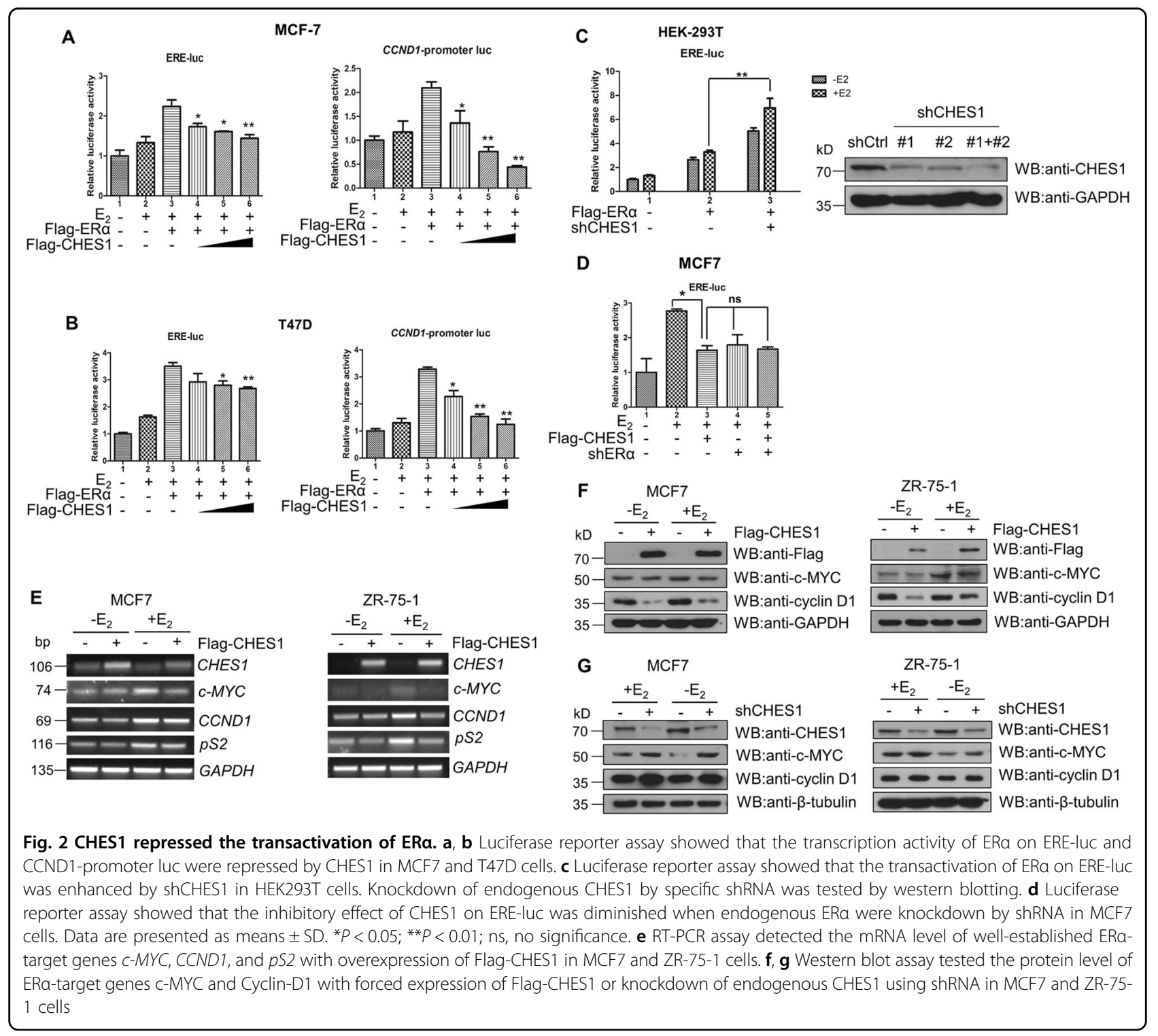


was detected between purified Glutathione S-transferase GST-CHES1 and endogenous ER $\alpha$ in MCF7 cells (Fig. 1e, f).

Moreover, in order to validate which region of the two proteins mediated the interaction, several deletion mutants of CHES1 and ER $\alpha$ were constructed as described previously ${ }^{33,39}$. GST-pulldown and CoIP assays showed that the FOX domain of CHES1 and the residues 282-595 of ER $\alpha$ are required for their physical interaction (Fig. 1f,g). Taken together, these results indicate that a physical interaction between CHES1 and ER $\alpha$ may exist in breast cancer cells.

\section{CHES1 represses the transcriptional activity of ERa}

To investigate the effect of the interaction between $E R \alpha$ and CHES1 on the transactivation of ER $\alpha$, luciferase reporter assay was conducted in ER $\alpha$-positive breast cancer cells. Overexpression of CHES1 attenuated the estrogen-dependent transcriptional activity of ER $\alpha$ in MCF7 and T47D cells when using ERE-luc and CCND1promoter luc (Fig. 2a,b). Then the similar assay was performed in ER $\alpha$-negative/CHES1-high expressing HEK293T cells. Knockdown endogenous CHES1 by short hairpin RNA (shRNA) significantly enhanced the transactivation of Flag-ER $\alpha$ (Fig. 2c). To further confirm the transcriptional repression of CHES1 on ER $\alpha$ transactivation depended on ER $\alpha$, stably knockdown of ER $\alpha$ was performed in MCF7 cells as described previously ${ }^{40}$. Luciferase reporter assay showed that the repression effect of CHES1 was diminished when ER $\alpha$ expression was interfered (Fig. 2d). Together, those results indicate that CHES1 may specifically repress ER $\alpha$-mediated transcriptional activity in ER $\alpha$-positive breast cancer cells.
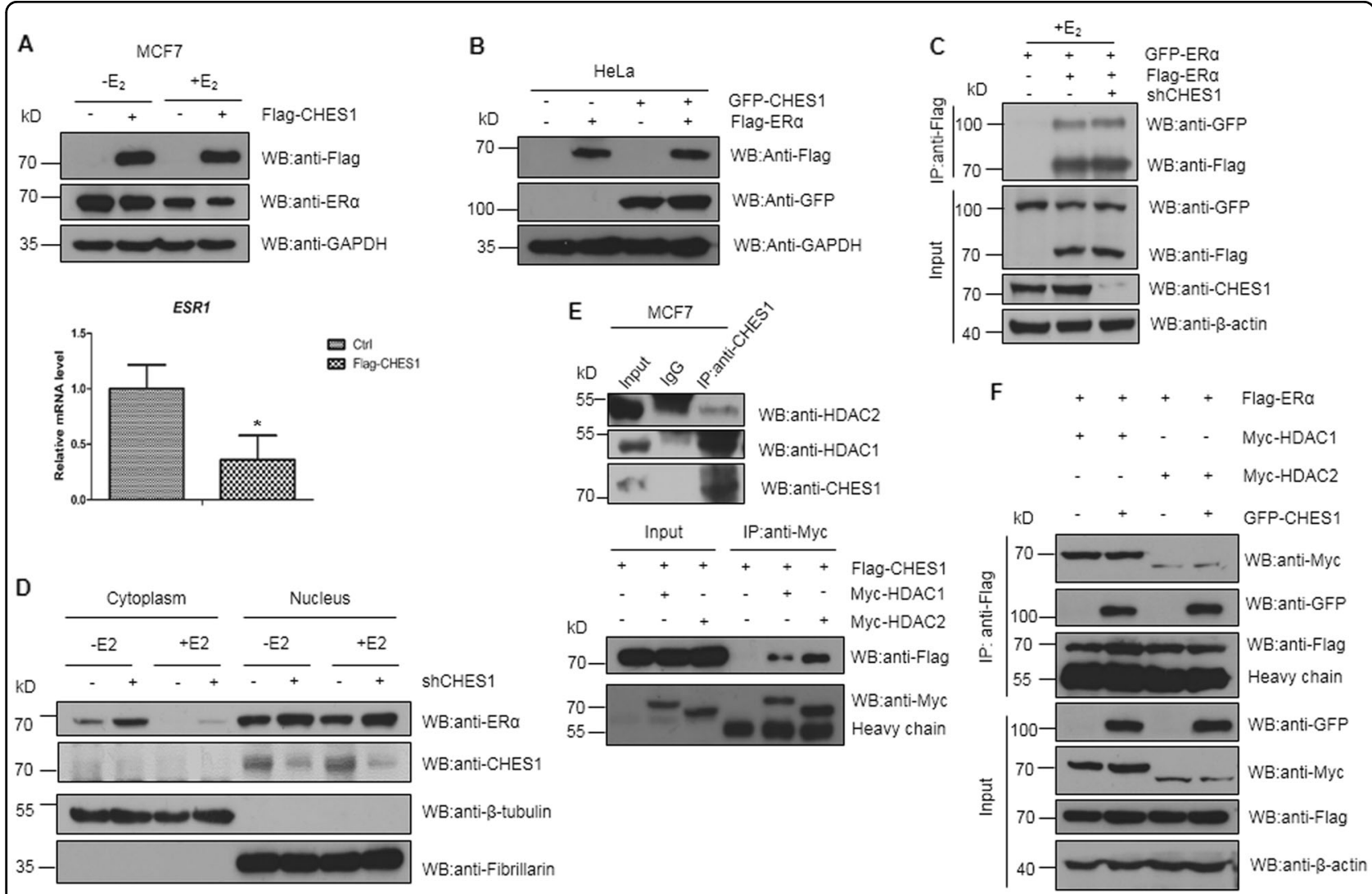

Fig. 3 CHES1 has little effect on the stability, dimerization, subcellular location of ERa, and it also does not influence the interaction between ERa and HDAC1/2. a Western blotting and real-time PCR assays tested the mRNA and protein level of endogenous ERa with overexpression of Flag-CHES1 in MCF7 cells. b Western blotting assay showed that the protein level of exogenous ERa were not affected when cotransfected with CHES1 in HeLa cells. c ColP assay indicated that the dimerization of ERa were not interfered with knockdown of CHES1 in HEK293T cells. d Cytoplasmic and nucleus fractions separation assay were conducted in MCF7 cells with or without knockdown of CHES1 to test the subcellular distribution of endogenous ERa. The $\beta$-tubulin used as cytoplasmic marker and Fibrillarin as nuclear marker. e CoIP assay showed the endogenous and exogenous interaction between CHES1 and HDAC1/2 in MCF7 and HEK293T cells. $\mathbf{f}$ CoIP assay assessed the effect of CHES1 on the interaction between ERa and HDAC1/2 


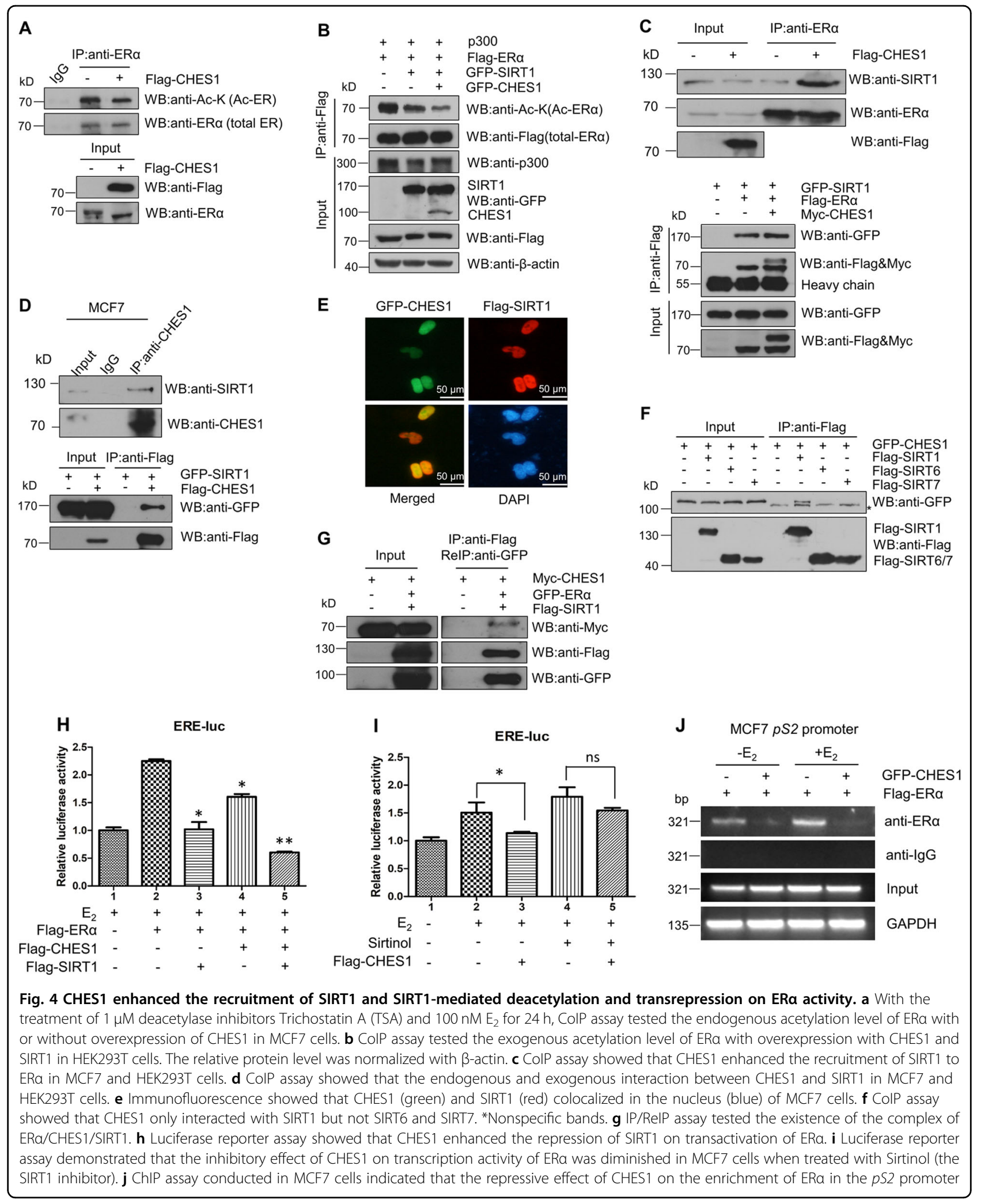

To further consolidate the observation, we tested the inhibitory effect of CHES1 on the expression of wellestablished ER $\alpha$ target genes (CCND1, $-M Y C$, and $p S 2$ ) in MCF-7 and ZR-75-1 cells. Further results showed that overexpression of CHES1 attenuated both mRNA and protein levels of these genes (Fig. 2e,f). Reciprocally, 
knockdown of endogenous CHES1 enhanced the protein level of Cyclin D1 and c-MYC (Fig. 2g). Together, these data support a notion that CHES1 may repress the transactivation of $E R \alpha$ via physical interaction in $E R \alpha$ positive breast cancer cells.

\section{CHES1 enhances SIRT1-mediated deacetylation of ERa and repression on ERa activity}

To further establish the detailed mechanism that the inhibitory effect of CHES1 on the transactivation of ER $\alpha$, we first tested whether CHES1 had influence on transcriptional expression of ER $\alpha$. The results showed that the mRNA and protein levels of ER $\alpha$ were repressed with overexpression of Flag-CHES1 in MCF7 cells (Fig. 3a); these results consist with the study reported by others ${ }^{20}$. However, considering the existence of interaction between CHES1 and ER $\alpha$, and how this interaction affect ER $\alpha$ activity remains to be illuminated. Therefore, we first tested whether the protein stability of ER $\alpha$ was affected by CHES1, because FOXK2, another member of FOX family, was established to promote degradation of $E R \alpha^{37}$. Co-transfection with Flag-ER $\alpha$ and GFP-CHES1 in HeLa cells showed that the ER $\alpha$ stability was not significantly changed by CHES1 (Fig. 3b). As ER $\alpha$ exhibits its function via forming homodimer in response to $E_{2}$ stimulation and then transferring into nuclear, we first tested whether the formation of ER $\alpha$ homodimer was disturbed by CHES1. The result showed that CHES1 did not have a significant effect on ER $\alpha$ dimerization (Fig. 3c). Moreover, the subcellular location of ER $\alpha$ was tested with knockdown of CHES1. Cytoplasmic and nuclear fractionation and immunofluorescence assays showed that CHES1 had little effect on the subcellular distribution of ER $\alpha$ in MCF7 cells (Fig. 3d and Figure S1A). It is commonly known that HDAC1 and HDAC2 both act as co-repressors of ER $\alpha$ and CHES1 could also recruit HDAC1/2 complex to achieve transcriptional suppressing function; it is necessary to elucidate that whether the interaction between HDAC1/ 2 and ER $\alpha$ were interfered by CHES1. To demonstrate this possibility, the interaction between CHES1 and HDAC1 or HDAC2 were confirmed by IP assay first (Fig. 3e). Then another IP assay indicated that CHES1 had little effect on the interactions between ER $\alpha$ and HDAC1/2 (Fig. 3f).

As the HDACs can also deacetylate non-histone proteins, the dynamic acetylation and deacetylation of nonhistone proteins are in charge of various proteins activity $^{41,42}$. It has been confirmed that the transactivation of $E R \alpha$ is coupled with acetylation and deacetylation mediated by $\mathrm{p} 300^{12,13}$ and deacetylase such as SIRT1 ${ }^{43,44}$. As we have proved that CHES1 could repress the transactivation of $E R \alpha$ and also exhibit its function via recruiting $\mathrm{HDACs}^{20,45}$, it proposed that CHES1 may regulate ER $\alpha$ acetylation to achieve transcriptional repression via recruiting deacetylases SIRT1. To support this possibility, the acetylation level of endogenous and exogenous ER $\alpha$ were tested by IP assays in MCF-7 and HEK293T cells. The data showed that overexpression of CHES1 attenuated the acetylation level of ER $\alpha$ (Fig. 4a,b). Then we speculated CHES1 may enhance the recruitment of the deacetylase SIRT1 to ER $\alpha$ and then induce SIRT1mediated deacetylation of ER $\alpha$. To test this notion, IP assay was conducted and the results showed that CHES1 could enhance the endogenous and exogenous interaction between ER $\alpha$ and SIRT1 (Fig. 4c).

To further consolidate this possibility, the interaction between CHES1 and SIRT1 was confirmed by IP, immunofluorescence, and GST-pulldown assays (Fig. 4d,e and S1D). In addition, further IP assay indicated that CHES1 can only interact with SIRT1 but not with other nucleus located Sirtuins (SIRT6 or SIRT7) (Fig. 4f). Given that CHES1 could both interact with SIRT1 and ER $\alpha$, we speculated that an ER $\alpha$-CHES1-SIRT1 complex might exist. To investigate this notion, IP/ReIP assay was conducted and the positive band was detected (Fig. 4g). The luciferase reporter assay also indicated that CHES1 enhanced SIRT1mediated repression on ER $\alpha$ transactivation (Fig. 4h). To further confirm that CHES1 repressed ER $\alpha$-mediated transcription activity via deacetylase SIRT1, Sirtinol, the selective inhibitor of SIRT1 ${ }^{46}$, was introduced in luciferase reporter assay. The repressive ability of CHES1 on ERE-luc diminished when the activity of SIRT1 has been inhibited by Sirtinol (Fig. 4i). Given that ER $\alpha$ acetylation enhances its DNA-binding activity and transactivation, chromatin immunoprecipitation (ChIP) assay was conducted to demonstrate the effect of CHES1 on the DNA-binding enrichment of ER $\alpha$ at $p S 2$ promoter in MCF7 cells. The result showed that the abundance of ER $\alpha$ in the promoter was attenuated when overexpressed CHES1 (Fig. 4j). Totally, these results indicate CHES1 may inhibit ER $\alpha$ transactivation and promoter occupancy enrichment via enhancing SIRT1 recruitment and the SIRT1-mediated deacetylation of ER $\alpha$.

\section{CHES1 expression is suppressed by $E_{2}$-ERa in breast cancer}

As described previously, genechips data identified that the expression of CHES1 was decreased in ER $\alpha$-positive cells MCF7 and ER $\alpha$ stably expressing MDA-MB-231 cells when treated with $\mathrm{E}_{2}{ }^{47}$; these results indicate a possibility that $C H E S 1$ may be regulated by $\mathrm{E}_{2}$-ER $\alpha$ signaling in breast cancer cells. To verify this hypothesis, CHES1 expression was detected in MCF7 cells treated with or without $E_{2}$. As results shown, endogenous CHES1 was decreased in response to $\mathrm{E}_{2}$ treatment (Fig. 5a). To further consolidate this possibility, 4-Hydroxytamoxifen (an $E_{2}$ agonist) and ICI 182780 (an ER $\alpha$ specific inhibitor) were introduced to antagonize $E_{2}$ stimulation. Consistently, the drugs reversed the inhibitory effect of $\mathrm{E}_{2^{-}}$ $E R \alpha$ on the expression of CHES1 (Fig. 5b). As shown in Fig. 3b, ER $\alpha$ may have little effect on the stability of 


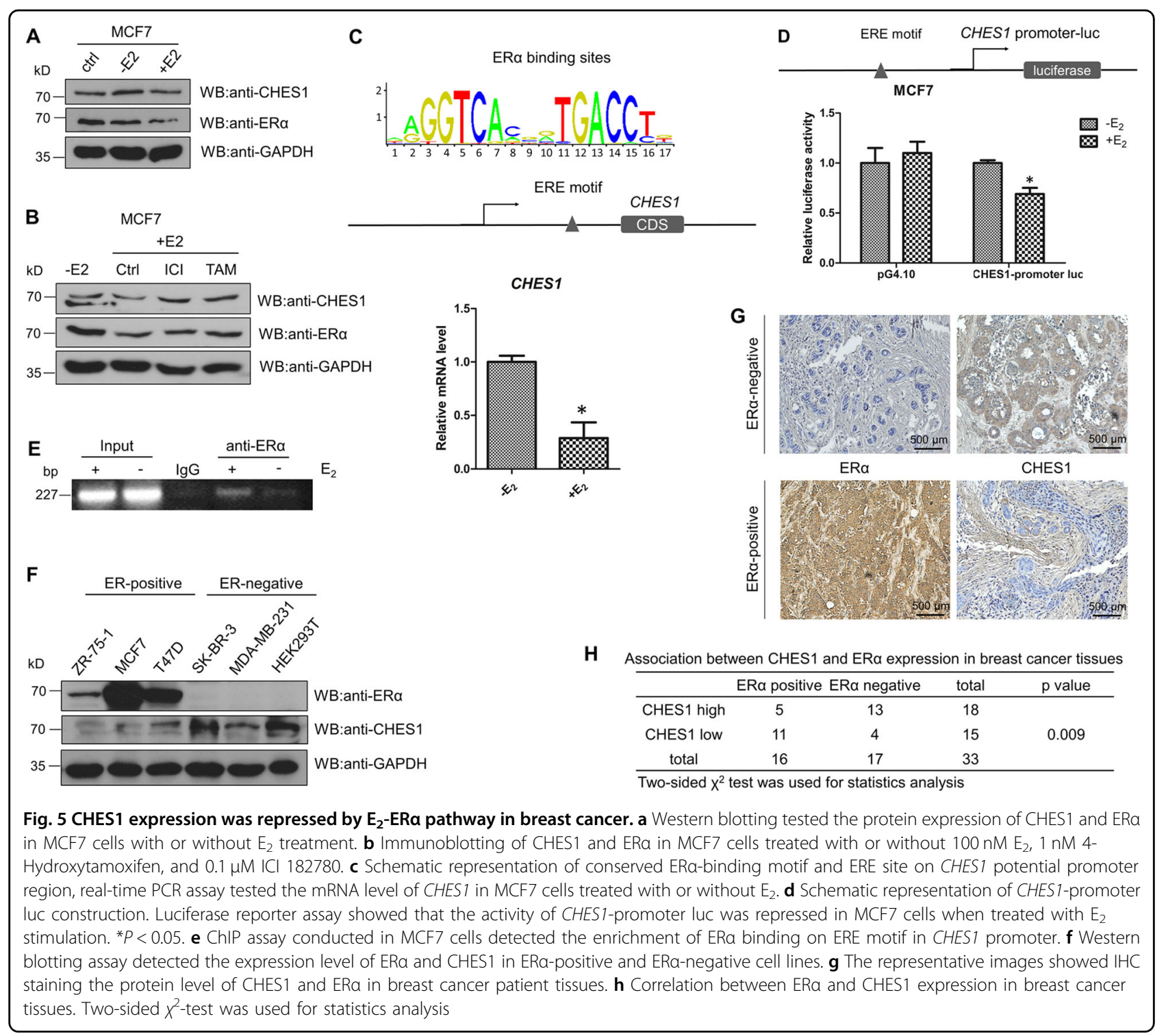

CHES1, so the inhibitory effect of $E_{2}$-ER $\alpha$ on CHES1 may be achieved via transcriptional level. Then, real-time PCR results confirmed that CHES1 mRNA level was largely decreased in ER $\alpha$-positive breast cancer cells MCF7 when responding to $\mathrm{E}_{2}$ stimulus (Fig. $5 \mathrm{c}$ ). Moreover, a conserved ERE was found at -2048 to -2064 bp region upstream of the Coding sequence (CDS) in potential promoter of CHES1 (Fig. 5c). Then, the CHES1-promoter luc covered $1000 \mathrm{bp}$ DNA fragment containing the conserved ERE was constructed using pGL4.10 vector. MCF7 cells transfected the construct showed a significantly decreased luciferase activity when treated with $\mathrm{E}_{2}$, but similar effect was not detected when using the control vector (Fig. 5d). In addition, the binding of ER $\alpha$ on this region was confirmed by ChIP assay (Fig. 5e).
Furthermore, the expression levels of CHES1 and ER $\alpha$ in different cell lines were tested by western blotting. The results showed that ER $\alpha$-positive breast cancer cells owned a lower level of CHES1, whereas ER $\alpha$-negative breast cancer cells had a higher level (Fig. 5f). To extend our observations to clinicopathologically relevant contexts, $16 \mathrm{ER} \alpha$-positive and $17 \mathrm{ER} \alpha$-negative breast carcinoma samples were collected to analyze the protein levels of CHES1 and ER $\alpha$ by immunohistochemical staining assay. Consistently, the results and statistics analysis showed that a significantly reverse association between CHES1 and ER $\alpha$ existed in breast cancer tissues (Fig. 5g,h). To further confirm this observation, analysis of a public dataset Oncomine (https:// www.oncomine.org/resource/login.html) also revealed that ER $\alpha$-positive breast cancer showed a lower level of CHES1 
and ER $\alpha$-negative breast cancer owned a higher one (Figure S2). Together, these results reveal that CHES1 expression may be repressed by $\mathrm{E}_{2}$-ER $\alpha$ in breast cancer.

\section{CHES1 inhibits proliferation and tumorigenesis of ERa- positive breast cancer cells}

As ER $\alpha$ is required for the proliferation of hormoneresponsive breast cancer cells, the association between CHES1 and ER $\alpha$ may have a role in ER $\alpha$-mediated growth of breast carcinoma. To test this hypothesis, cell proliferation assay was conducted in ER $\alpha$-positive breast cancer cells MCF7 and T47D. The results indicated that the growth activities of MCF7 and T47D cells were significantly repressed with overexpression of Flag-CHES1 (Fig. 6a,b) and knockdown of CHES1 enhanced the cell viability (Figure S4C). To further consolidate this observation, colony formation and soft-agar colony culture assays were also performed, and the results showed that overexpression of CHES1 resulted in a marked decrease in colony formation number and knockdown of CHES1 increased the colony formation (Fig. 6c,d). In addition, cell cycle assay also demonstrated that the cell cycle of T47D cells was arrested with ectopic expression of CHES1, whereas the cell cycle process of ER $\alpha$-negative cells HeLa was not affected (Fig. 6e). These data indicated that CHES1 may specifically repress ER $\alpha$-mediated proliferation and cell cycle process in vitro. Moreover, human breast cancer xenograft mouse model was constructed to investigate the role of CHES1 in tumorigenesis of breast cancer in vivo. Host with stable expression of Flag-CHES1 exhibited much smaller size in tumor volume and tumor weight compared with the control group (Fig. 7a-c). In addition, we further tested the expression level of ER $\alpha$ target genes (CCND1 and c-MYC) and proliferation biomarker Ki67 in these tumors. The immunohistochemistry (IHC) staining results confirmed that CHES1 significantly repressed the ER $\alpha$ target genes expression and inhibited the growth ability of breast cancer cells (Fig. 7d). Bioinformatics analysis also showed that CHES1 expression was significantly downregulated in breast cancer tissues compared with normal ones, which indicated CHES1 may act as a tumor suppressor in breast cancer (Figure S3) ${ }^{48}$. More importantly, we also evaluated the association between CHES1 level and the prognosis of breast cancer patients from a microarray data set of breast tumors $^{49}$. Among 3951 total breast cancer and 3082 $E R \alpha$-positive breast cancer patients, the patients with high CHES1 expression level had much longer relapsefree survival time than those with low level (Fig. 7e). Together, these results indicated that CHES1 exhibits an inhibitory effect on the proliferation and tumorigenesis potential of ER $\alpha$-positive breast cancer cells in vitro and in vivo, and the high level of CHES1 may indicate a better prognosis.

\section{Discussion}

Studies have confirmed that ER $\alpha$ acts as a key regulator for hormone-responsive breast cancer and is required for the growth of ER $\alpha$-positive breast cancer. In addition, clinical researches have demonstrated that ER $\alpha$ is one of the most successful molecular targets for drug therapy ${ }^{1}$. However, the comprehensive regulatory network of ER $\alpha$ in breast cancer has not been fully elucidated. Herein, we demonstrated that CHES1 could interact with ER $\alpha$ through its evolutionary conserved forkhead domain. Furthermore, CHES1 could repress ER $\alpha$-mediated transactivation in breast cancer cells but had little effect on the stability, cellular location and dimerization of ERo. Mechanistically, further data indicated that CHES1 could enhance the recruitment of deacetylase SIRT1 and promote SIRT1-mediated deacetylation of ER $\alpha$. Functionally, CHES1 formed a complex with ER $\alpha$ and SIRT1 and then decreased the acetylation level and promoterbinding enrichment of ER $\alpha$. In addition, we also detected a decrease mRNA and protein level of ER $\alpha$ with ectopic expression of CHES1 in MCF7 cells. This data consisted with a study reported recently that CHES1 could repress the transcriptional expression of ESR1 via an HADC1/2-dependent way $^{20}$. Considering that, CHES1 may regulate the activity of ER $\alpha$ through two ways in breast cancer cells. One is that CHES1 repressed the transcriptional expression of $E R \alpha$ in an HDAC1/2-dependent way; on the other hand, CHES1 directly interacted with ER $\alpha$ and then facilitated SIRT1-mediated deacetylation of ER $\alpha$ without involving HDAC1/2. Furthermore, our work also revealed that CHES1 not only interacted with class I HDAC1 and HDAC2, but also had association with class III deacetylase SIRT1. Which one CHES1 prefer to interact with or CHES1 could interact with all of these deacetylases simultaneously is also remained to be investigated. However, considering that the nuclear receptors can engage in multiple nuclear complexes to exhibit diverse actions of gene regulation ${ }^{50}$, an alternative explanation is that CHES1 acts as the co-regulator of ER $\alpha$ and participates in different transcriptional complexes, which are composed of different classes of deacetylase. Taken together, our study introduces an alternative model that the $E R \alpha$ transcriptional activity is regulated by CHES1 in breast cancer cells and reveals a novel way of CHES1 involved in transcriptional regulation.

Previous studies have reported that CHES1 expression is downregulated in many types of carcinoma and its expression level has tight association with malignancy progression and prognosis. Here we found that the CHES1 expression was repressed in ER $\alpha$-positive breast cancer cells when treated with $E_{2}$. Furthermore, we explored the molecular mechanism involved and identified a conserved ERE in the regulatory region of CHES1 promoter. Our results confirmed the possibility that $E_{2}-E R \alpha$ signaling pathway may have an inhibitory effect on the transcriptional expression of CHES1 and ER $\alpha$ could directly bind to the promoter of CHES1 by 


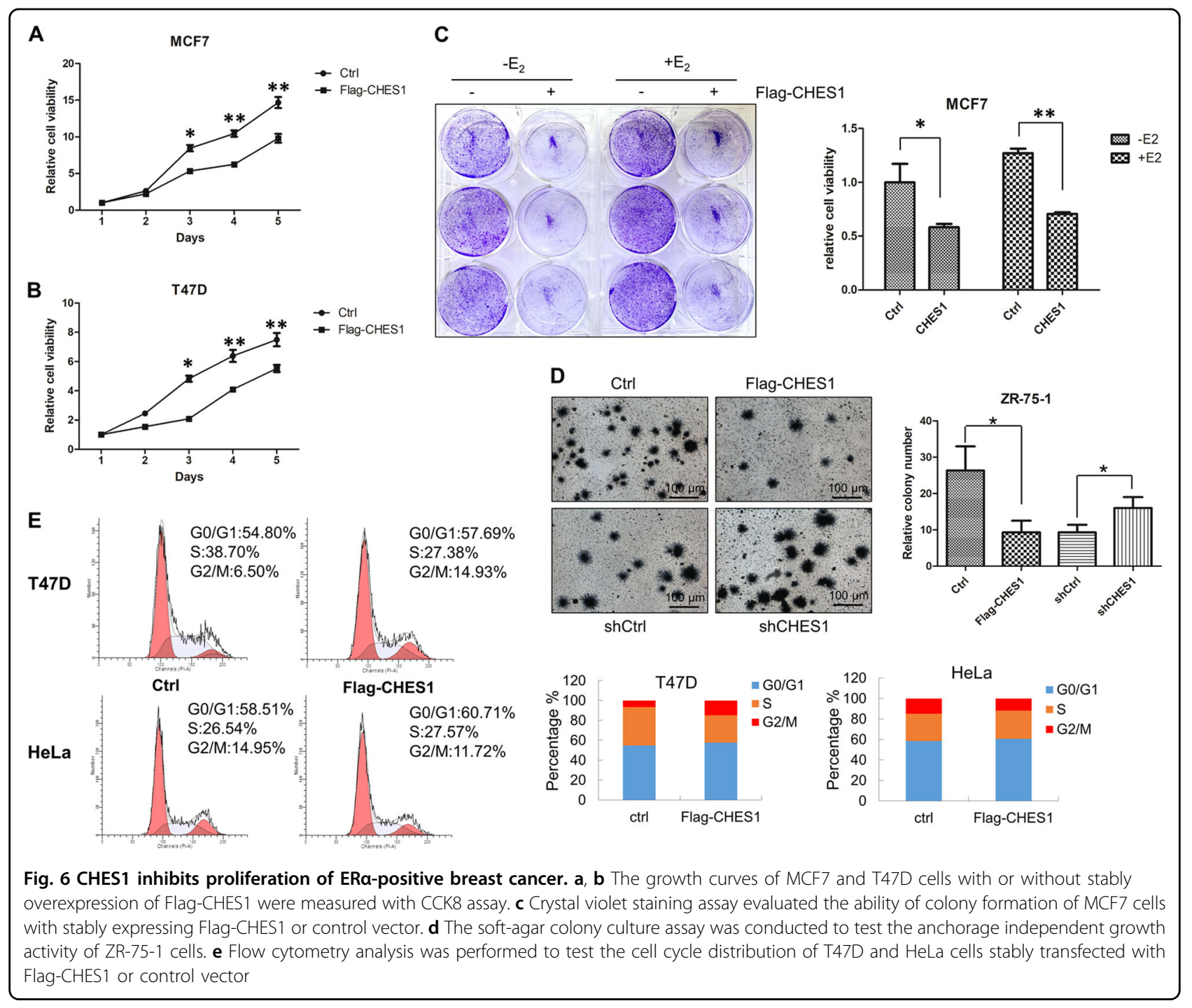

recognizing the ERE motif and further repress CHES1 transcription. Consistently, a negative association between ER $\alpha$ and CHES1 expression was identified in breast cancer cell lines and tumor tissues. In addition, we also confirmed this finding in public databases. Previous study and our results confirmed that CHES1 also reversely transrepressed ER $\alpha$ expression in ER $\alpha$-positive breast cancer ${ }^{20}$; hence, a negative regulatory loop between ER $\alpha$ and CHES1 may exist in ER $\alpha$ positive breast cancer (Fig. 8).

As previous studies indicated, CHES1 may act as a tumor-repressing protein in multiple cancer types such as colorectal carcinoma $^{30}$, hepatic carcinoma ${ }^{32}$, glioblastoma $^{31}$, and oral squamous cell carcinoma ${ }^{28}$. Consistently, the study here revealed that CHES1 could inhibit ER $\alpha$-mediated proliferation and tumorigenesis through physical association with ER $\alpha$ in breast cancer cells. However, a study showed that CHES1 promoted epithelial-to-mesenchymal transition (EMT) in hormone- responsive breast cancer ${ }^{20}$, which indicated CHES1 may exhibit oncogenic functions. However, EMT is relatively uncorrelated and independent with proliferation processes, and the gene expression profile and regulatory network of EMT are largely far from growth and proliferation $^{51}$. Furthermore, many molecules and signaling pathways may serve as dual roles in the processes of growth and $\mathrm{EMT}^{43,44,52,53}$, such as transforming growth factor- $\beta 1^{52,53}$ and SMADs ${ }^{54}$. Therefore, the role of CHES1 had in EMT and growth may be tightly dependent on signaling crosstalk or different partners in specific cellular environment.

In the present study, we revealed that CHES1 may have a role in ER $\alpha$-positive breast cancer, but the defined biological role of CHES1 in other subtypes of breast cancer has not been fully elucidated. We also found that high CHES1 expression level indicated a better prognosis in patients with ER $\alpha$-negative breast cancer (Figure S4F). 


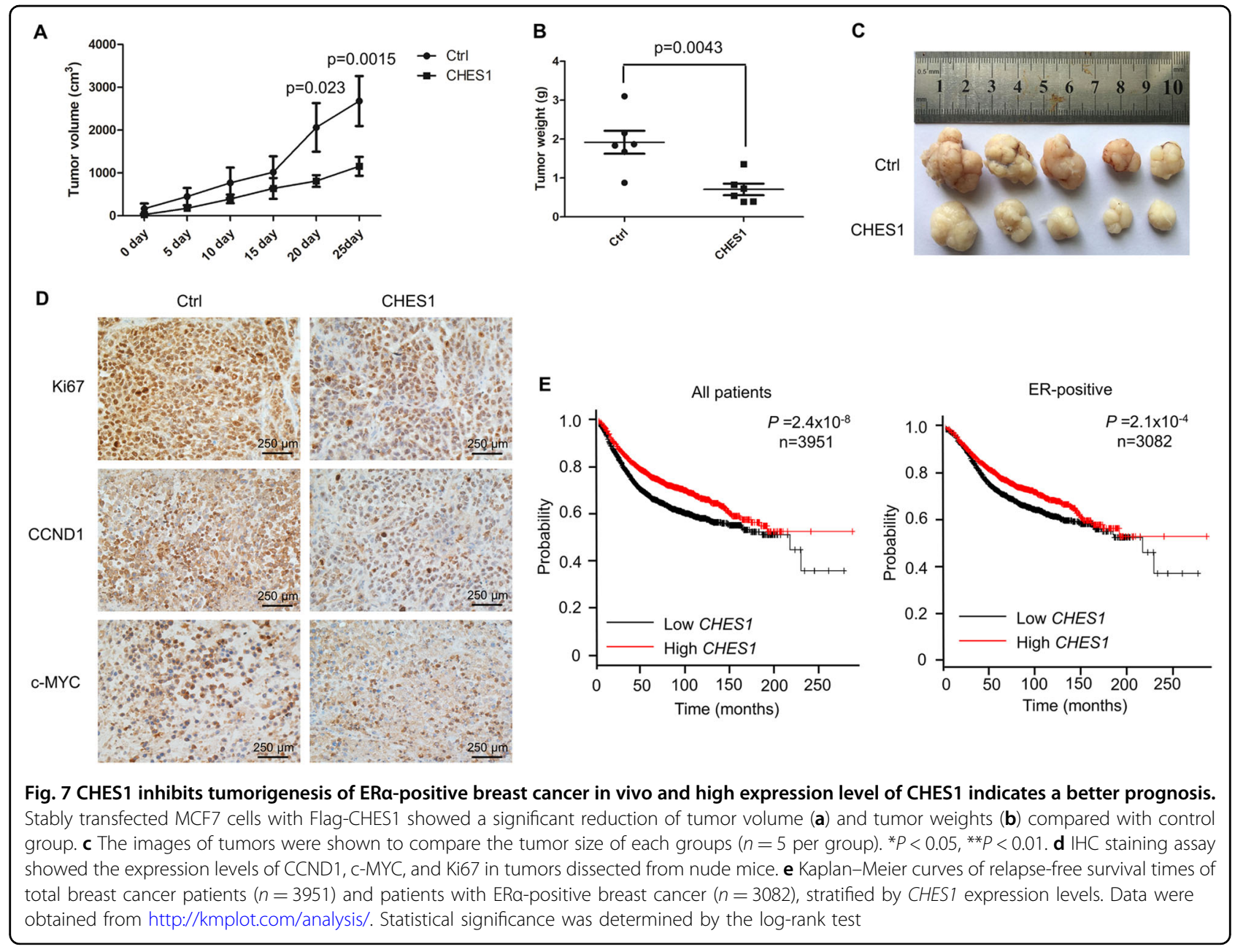

In addition, the interaction between CHES1 and SIRT1 not only existed in ER $\alpha$-positive breast cancer cells but in many ER $\alpha$-negative cells (Fig. S1B-1D). These results indicated that the association between CHES1 and SIRT1 may exhibit other biological function not completely dependent on ER $\alpha$. What's more, previous studies demonstrated that CHES1 may regulated many genes (such as KLF4 and $c-M Y C$ ) and signaling pathways (such as Wnt/ $\beta$-catenin) aberrantly active in ER $\alpha$-negative breast cancer ${ }^{20,27}$. Therefore, the function of CHES1 involved in ER $\alpha$-negative breast cancer needs further investigation. In order to explore the role of CHES1 in clinical research, we treated MCF7 and T47D cells with three widely used chemotherapy drugs - Cisplatin, Paclitaxel, and Topotecan $\mathrm{HCl}$-and then tested the association between CHES1 and chemotherapeutic sensitivity. The results showed that knockdown of CHES1 had little effect on drug sensitivity (Figure S4A and S4B) but indeed enhanced the proliferation ability of ER $\alpha$ positive breast cancer cells (Figure S4C). Furthermore, we also found that the overall survival of breast cancer patients who only received chemotherapy treatments have little correlation with the CHES1 expression (Figure S4G). As these chemotherapeutic drugs exhibit their function via inducing apoptosis, an alternative explanation is that CHES1 may not enhance the apoptosis process induced by these drugs. As our study focused on ER $\alpha$, we also tested the role of CHES1 in endocrine therapy and treated MCF7 cells with Tamoxifen. However, the results indicated that the Tamoxifen sensitivity of MCF7 cells were not affected by shCHES1 (Figure S4D). A possibility is that acetylation of ER $\alpha$ regulated by CHES1 may not affect the hormones sensitivity. Nonetheless, whether CHES1 affects the drug sensitivity of breast cancer cells or not, it needs further extensive drug screening and certification.

\section{Materials and methods \\ Plasmids and reagents}

Flag-tagged CHES1 and its control vector plpc- $3 \times$ Flag were gifts kindly provided by Dr Gerardo Ferbeyre (Université de Montréal, Canada).The CDS of full-length 


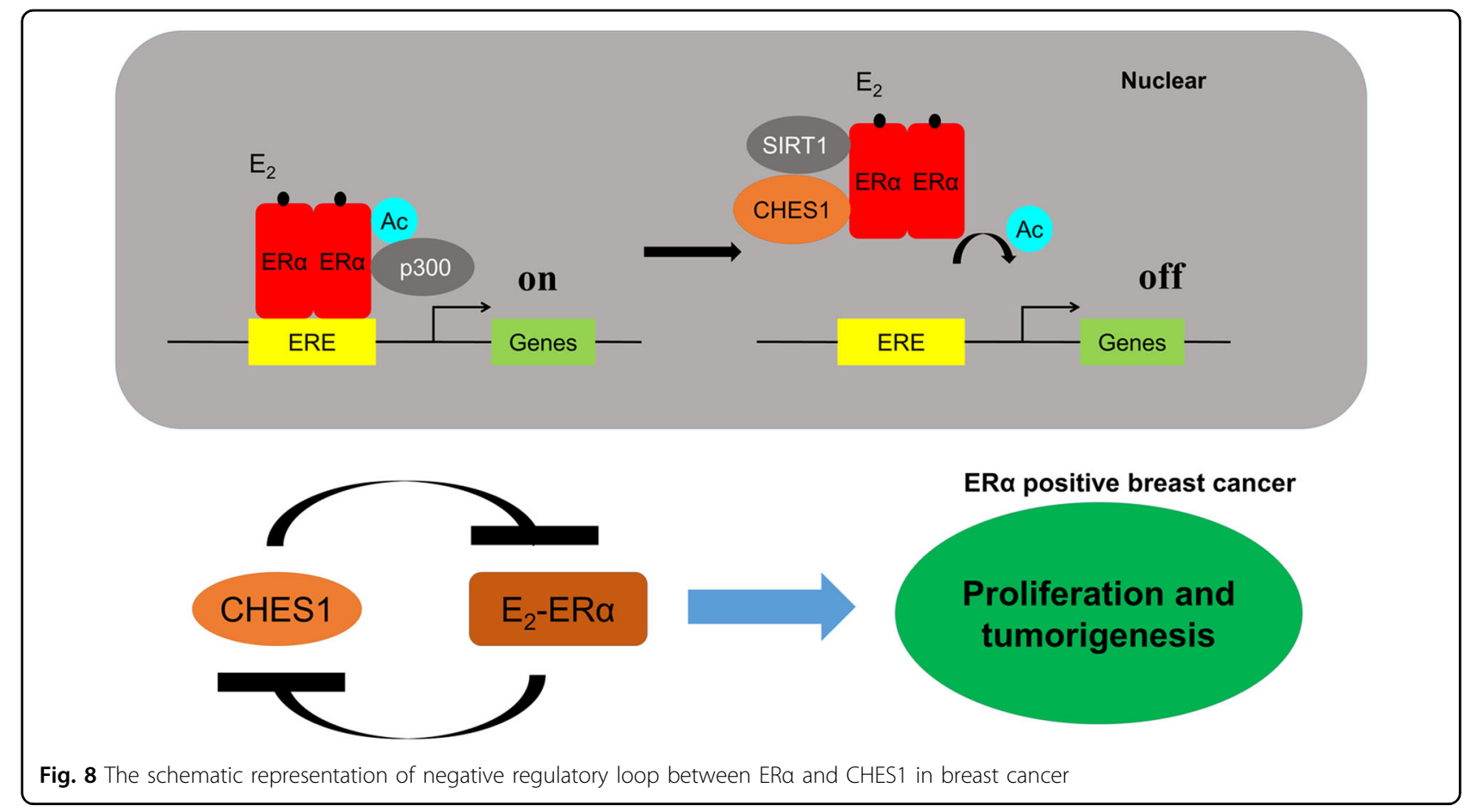

CHES1, $\triangle \mathrm{C}$, and $\triangle \mathrm{FN}$ mutants were constructed by standard PCR using specific primers and Flag-CHES1 as template. Green fluorescent protein (GFP)-tagged fulllength protein and deletion mutants were obtained by PCR and then cloned into GFP-C1 vector at the XhoI and EcoRI sites. GST-tagged full-length and truncated CHES1 were constructed using similar methods by cloning PCR fragments into pGEX-4T-3 (Amersham Pharmacia, UK). Myc-CHES1 was obtained by using pcDNA3.1-Myc expression vector. Flag-tagged full-length and truncated $E R \alpha$ have been previously described ${ }^{39}$. Flag-SIRT1, FlagSIRT6, Flag-SIRT7, and GFP-SIRT1 were kindly gifted by Dr Jeong Hoon Kim (Sungkyunkwan University, Korea). shER $\alpha$ has been used in our previous study ${ }^{40}$. CHES1 shRNA expression vectors were constructed by DNA vector-based shRNA synthesis by using the vector pRNATU6.1. The shRNA effects were verified by results of western blotting.

Rabbit polyclonal antibody against $\mathrm{ER} \alpha(\mathrm{HC}-20)$, mouse monoclonal $\beta$-actin (C-2), Fibrillarin (F-6), and SIRT1 (B10) were obtained from Santa Cruz Biotechnology (Santa Cruz). Rabbit polyclonal antibodies against CHES1 was purchased from Abcam (ab129453) and Abgent (AP19255B). Mouse monoclonal anti-GST antibody (ABN116) was obtained from Millipore. Rabbit polyclonal anti-GFP (GTX113617) antibody was purchased from GeneTex. Rabbit polyclonal anti-c-MYC (SAB4501941), mouse monoclonal anti-Flag (M2) antibodies, and 4Hydroxytamoxifen (H6278) were purchased from Sigma. Rabbit polyclonal anti-CCND1 (D160236) were obtained from BBI Life Science. Rabbit polyclonal anti-Acetylated lysine (9441) antibody was purchased from CST. ICI 182780 was used as previously described ${ }^{40}$. Rabbit polyclonal anti-Ki67 (27309-1-AP) antibody was purchased from Proteintech. Sirtinol (HY-13515), the specific inhibitor of SIRT1, was obtained from MCE. Cisplatin, Paclitaxel,and Topotecan $\mathrm{HCl}$ were purchased from Selleck.

\section{Cell culture and transfection}

HEK293T, COS-7, HeLa, and MDA-MB-231 cells were used in our previous studies ${ }^{37,55,56}$. ZR-75-1, MCF-7, T47D, and SK-BR-3 cells were kindly provided by Dr Wei Cheng of Dalian Medical University. HEK293T, COS-7, HeLa, and MDA-MB-231 cells were cultured in Dulbecco's modified Eagle's medium (DMEM, Invitrogen) containing $10 \%$ fetal bovine serum (Hyclone) and penicillin-streptomycin $(100 \mathrm{U} / \mathrm{ml}$ penicillin and $0.1 \mathrm{mg} /$ $\mathrm{ml}$ streptomycin). ZR-75-1 cells were cultured in RPMI1640 medium supplemented with $10 \%$ fetal bovine serum and penicillin-streptomycin. T47D cells were cultured in similar complete RPMI-1640 medium in addition with 2 Units/ml bovine insulin. MCF7 cells were cultured in Eagle's minimum essential medium containing $10 \%$ fetal bovine serum, penicillin-streptomycin, and $0.01 \mathrm{mg} / \mathrm{ml}$ human recombinant insulin. SK-BR-3 was cultured in McCoy's $5 \mathrm{a}$ medium modified base medium supplemented with $10 \%$ fetal bovine serum and penicillin-streptomycin. All cell cultures were incubated at $37^{\circ} \mathrm{C}$ in the presence of $5 \% \mathrm{CO}_{2}$. Transfection assays 
were carried out using Lipofectamine 2000 (Invitrogen) according to the manufacturer's instruction.

\section{Luciferase reporter assay}

HEK293T and MCF7 cells transfected with the appropriate plasmids were starved for $24 \mathrm{~h}$ with phenol red-free medium containing $2 \%$ charcoal-stripped fetal bovine serum (Gibico). Then the medium were replaced by treatment with or without $100 \mathrm{nM} \mathrm{E}_{2}$ for $16 \mathrm{~h}$. The cells were then subjected to luciferase reporter assay. Relative luciferase activity was normalized to $\beta$-galactosidase and shown as fold changes.

\section{Immunoprecipitation and western blotting}

Cells were collected with the lysis buffer $(50 \mathrm{mM}$ Tris$\mathrm{HCl} \mathrm{pH} \mathrm{7.4,} 150 \mathrm{mM} \mathrm{NaCl}, 0.1 \%$ SDS, 1\% NP-40, 0.5\% sodium deoxycholate, and protease inhibitor cocktail (Sigma)). After centrifugation at $12,000 \times g$ for 15 min at 4 ${ }^{\circ} \mathrm{C}$, the supernatant was incubated with the desired antibody or with control IgG and protein A-sepharose (GE) at $4{ }^{\circ} \mathrm{C}$ for $4 \mathrm{~h}$. After centrifugation at $3000 \times g$ for $10 \mathrm{~min}$ at $4{ }^{\circ} \mathrm{C}$, the supernatant was abandoned and the precipitate was subjected to wash three time with lysis buffer. Then the pellets was suspended with SDS-polyacrylamide gel electrophoresis (PAGE) $2 \times$ loading buffer, boiling at $100^{\circ} \mathrm{C}$ for $5 \mathrm{~min}$ and subjected to SDS-PAGE. After electrophoresis, proteins were separated and blotted onto a polvinylidene difluoride membrane (Millipore). Membranes were probed with the specific primary antibody and then peroxidase-conjugated secondary antibodies. The bands were visualized by chemiluminescence.

\section{Immunofluorescence assay}

Immunofluorescence assay was conducted as described previously $^{57}$.

\section{In vivo tumorigenesis study}

All animal experiments and immunohistochemical analysis were approved by the Ethics Committee for Biology and Medical Science of Dalian University of Technology. Human breast cancer xenograft model was constructed as preciously described ${ }^{57}$. Five- to 6-week-old female athymic nude mice (BALB/c mice) were obtained from Animal Experiment Center of Dalian Medical University. Animals were randomly assigned to different groups and each group contained seven animals. Stably transfected tumor cells $\left(1 \times 10^{6}\right)$ in $100 \mu$ l of growth medium (mixed with Matrigel (Corning) at 1:1 ratio) were injected subcutaneously. Tumor growth was facilitated by feeding the animals with water containing $E_{2}$ at a concentration of $1 \mathrm{mg} / \mathrm{l}$. Tumor size were measured once five days using a caliper two weeks post injection. Tumor volume were calculated using the standard formula $0.5 \times$
$L \times W^{2}$, where $L$ is the longest diameter and $W$ is the shortest diameter. Mice were killed after 45 days and the tumor were removed, photographed, and weighed.

\section{GST-pulldown assay}

The GST pulldown assay was carried out as previously described $^{58}$. The GST alone and GST-fusion proteins were expressed in Escherichia coli BL21 (Takara) and purified using Pierce GST Spin Purification Kit (Thermo scientific) as per the manufacturer's instruction. The purified proteins were subjected to immobilized on the Pierce Spin Column and then preyed ER $\alpha$ from MCF-7 cells lysate.

\section{Cell proliferation assay}

Cells were stably transfected with different plasmids and then plated in 96-well plate. Cell proliferation assay were performed using Cell Counting Kit-8 purchased from Solarbio Life Science as manufacture's instruction. Crystal violet staining assay was carried out by plating $1 \times 10^{4}$ cells in six-well plate. Then cells were grown in with or without $E_{2}$ for a week and subjected to crystal violet staining as previously described. ${ }^{37}$ After staining, wells were washed three times with phosphate-buffered saline and destained with acetic acid, and the absorbance of the crystal violet solution was measured at $590 \mathrm{~nm}$. For cell cycle assay, cells were transfected with the appropriate plasmids and subjected to Flow Cytometry assay with PI staining. Data were collected by FACSCalibur (BD Biosciences). Results were analyzed using ModFit software (BD Biosciences).

\section{Drug sensitivity assay}

Cells were stably transfected with different plasmids and then plated in 96-well plate. Then incubated with different concentration of drugs for indicated time, the cell viability were measured by CCK8 assay.

\section{Anchorage-independent growth assay}

The soft-agar colony culture assay was performed as previously described ${ }^{57}$. Cells $\left(2 \times 10^{3}\right)$ were suspended in $1 \mathrm{ml}$ of $0.3 \%$ low-melting-point agarose mixed with $2 \times$ DMEM at 1:1 ratio and plated in triplicate in six-well plate on $1 \mathrm{ml}$ of presolidified $0.7 \%$ agarose in the same medium. Then add $1 \mathrm{ml}$ medium to cover the cells and cultured for 3-4 weeks. Cells were stained with MTT (3-(4,5-dimethylthiazol-2-yl)-2,5-diphenyltetrazolium bromide) and the number of colony was counted by using Image) program.

\section{RNA extract and RT-PCR}

The cells transfected plasmids indicated were subjected to total RNA extract using RNAiso reagents (Takara). The $2 \mu \mathrm{g}$ RNA then was reverse transcripted into cDNA using oligo- 
$\mathrm{dT}$ primer. The relative expression of genes was analyzed using standard PCR, the GAPDH was set as control. The primers used in RT-PCR were following listed: GAPDH, $5^{\prime}$ GGGTTGAACCATGAGAAGT-3' (forward), 5'-GACTG TGGTCATGAGTCCT-3' (reverse); ESR1, 5'- ACTCGC TACTGTGCAGTGTGCAAT-3' (forward), 5' - CCTCTTC GGTCTTTTCGTATCCCA-3' (reverse); c-MYC, 5' - AGG GATCGCGCTGAGTATAA-3' (forward), 5' - TGCCTCT CGCTGGAATTACT-3' (reverse); CCND1, 5' - GCTGCTC CTGGTGAACAAGC-3' (forward), 5' - AAGTGTTCAAT GAAATCGTGCG-3' (reverse); $p S 2$, 5' - ATGGAGAACAA GGTGATCTG-3' (forward), 5' - CCACAATTCTGTCTTT CACG-3' (reverse); CHES1, 5' - AAATGGAGCGCGGGTC CTGAG-3' (forward), 5' - GCAGCTGGTGATGCCATTCC $\mathrm{T}-3^{\prime}$ (reverse).

\section{Cytoplasmic and nuclear fractionation}

The separation of cytoplasmic and nuclear proteins was used Cytoplasmic and Nuclear Fractionation kit obtained from KeyGen BioTECK (Nanjing, China). The process of this assay was conducted as per the manufacturer's instruction.

\section{IHC staining assay}

IHC staining assay was performed as previously described $^{37,58}$. All the patient species were obtained from Qiqihar Medical University. In addition, 33 slides (17 ER $\alpha$ negative and $16 \mathrm{ER} \alpha$ positive) were incubated with CHES1 and ER $\alpha$ antibodies; the expression levels of CHES1 and $\mathrm{ER} \alpha$ were quantified according to their $\mathrm{H}$-scores. The IHC Kit was purchased from ZSGB-BIO (Beijing, China). All individuals who donated the tissues for this study gave their consent in written form. The expression levels of CCND1, c-MYC, and Ki67 in tumors were staining with antibodies as indicated.

\section{ChIP assay}

ChIP assay was carried out as previously described ${ }^{39}$. The lysate of MCF7 cells was immunoprecipitation with antibody against ER $\alpha$ and purified DNA fragment was analyzed by quantitative reverse transcription-PCR. The primers used in the ChIP PCR analysis were $5^{\prime}$-GGCCA TCTCACTATGAATCACTTCTGC-3' (forward) and 5'-GGCAGGCTCTGTTTGCTTAAAGAGCG-3' (reverse) for $p S 2$ promoter. The primer for ERE on CHES1 promoter were 5'-AAAGACAAGTGGTGCTATAATTC GT-3' (forward) and $5^{\prime}-$ TTAAGGAGAGAAAA CTTCATGAGGC-3' (reverse).

\section{Statistical analysis}

All the expriments were repeated at least three times. Data were presented as mean \pm SDs and Student's $t$-test (unpaired, two-tailed) was used to compare two groups of independent samples. $P<0.05$ was considered statistically significant.

\section{Acknowledgements}

We express gratitude to Dr. Gerardo Ferbeyre (Université de Montréal, Canada) for generously providing Flag-tagged CHES1 and its control vector pLpc-3 $\times$ Flag. We thank Dr Jeong Hoon Kim (Sungkyunkwan University, Korea) for his gifts of Flag-SIRT1, Flag-SIRT6, Flag-SIRT7, and GFP-SIRT1. We thank Dr Hongming Pan (Qiqihar Medical University) for providing the samples from breast cancer tissues. We thank Dr Wei Cheng (Dalian Medical University) for kindly providing MCF7, T47D, ZR-75-1, and SK-BR-3 breast cancer cells. This work was supported by grants ( 81672792 to HW) from National Natural Science Foundation of China and (DUT18LAB25 to HW) from the Fundamental Research Funds for the Central Universities.

Conflict of interest

The authors declare that they have no conflict of interest.

\section{Publisher's note}

Springer Nature remains neutral with regard to jurisdictional claims in published maps and institutional affiliations.

Supplementary Information accompanies this paper at (https://doi.org/ 10.1038/s41419-018-0629-3).

Received: 30 January 2018 Revised: 13 April 2018 Accepted: 18 April 2018 Published online: 11 May 2018

\section{References}

1. Shang, Y. \& Brown, M. Molecular determinants for the tissue specificity of SERMs. Science 295, 2465 (2002).

2. Zhou, W. \& Slingerland, J. M. Links between oestrogen receptor activation and proteolysis: relevance to hormone-regulated cancer therapy. Nat. Rev. Cancer 14, 26 (2014).

3. Liang, J. \& Shang, Y. Estrogen and cancer. Annu. Rev. Physiol. 75, 225-240 (2013).

4. Laganière, J. et al. Location analysis of estrogen receptor a target promoters reveals that FOXA1 defines a domain of the estrogen response. Proc. Natl Acad. Sci. USA 102, 11651-11656 (2005)

5. Fullwood, M. J. et al. An oestrogen receptor a-bound human chromatin interactome. Nature 462, 58-64 (2009).

6. Zhang, $\mathrm{H}$. et al. The catalytic subunit of the proteasome is engaged in the entire process of estrogen receptor-regulated transcription. EMBO J. 25, 4223 (2006).

7. Métivier, R. et al. Estrogen receptor-a directs ordered, cyclical, and combinatorial recruitment of cofactors on a natural target promoter. Cell 115, 751 (2003).

8. Murakami, S., Nagari, A. \& Kraus, W. L. Dynamic assembly and activation of estrogen receptor alpha enhancers through coregulator switching. Genes Dev. 31, 1535-1548, https://doi.org/10.1101/gad.302182.117 (2017).

9. Lonard, D. M., Nawaz, Z., Smith, C. L. \& O'Malley, B. W. The 265 proteasome is required for estrogen receptor-a and coactivator turnover and for efficient estrogen receptor-a transactivation. Mol. Cell. 5, 939 (2000).

10. Champagne, F. A. et al. Maternal care associated with methylation of the estrogen receptor-alpha1b promoter and estrogen receptor-alpha expression in the medial preoptic area of female offspring. Endocrinology 147, 2909-2915 (2006).

11. Chen, D., Pace, P. E., Coombes, R. C. \& Ali, S. Phosphorylation of human estrogen receptor a by protein kinase A regulates dimerization. Mol. Cell. Biol. 19, 1002-1015 (1999).

12. Wang, $C$. et al. Direct acetylation of the estrogen receptor alpha hinge region by p300 regulates transactivation and hormone sensitivity. J. Biol. Chem. 276, 18375-18383 (2001).

13. Mi, Y. K., Woo, E. M., Chong, Y. T. E., Homenko, D. R. \& Kraus, W. L. Acetylation of estrogen receptor alpha by p300 at lysines 266 and 268 enhances the DNA binding and transactivation activities of the receptor. Mol. Endocrinol. 20, 1479-1493 (2006). 
14. Sentis, S., Le, R. M., Bianchin, C., Rostan, M. C. \& Corbo, L. Sumoylation of the estrogen receptor alpha hinge region regulates its transcriptional activity. Mol. Endocrinol. 19, 2671 (2005)

15. Tremblay, A. M., Wilson, B. J., Yang, X. J. \& Giguère, V. Phosphorylationdependent sumoylation regulates estrogen-related receptor- $a$ and $-\gamma$ transcriptional activity through a synergy control motif. Mol. Endocrinol. 22 570-584 (2008).

16. Moore, R. L. \& Faller, D. V. SIRT1 represses estrogen-signaling, ligandindependent ERa-mediated transcription, and cell proliferation in estrogenresponsive breast cells. J. Endocrinol. 216, 273-285 (2013).

17. Lam, E. W. F., Brosens, J. J., Gomes, A. R. \& Koo, C. Y. Forkhead box proteins: tuning forks for transcriptional harmony. Nat. Rev. Cancer 13, 482 (2013).

18. Myatt, S. S. \& Lam, E. W.F. The emerging roles of forkhead box (Fox) proteins in cancer. Nat. Rev. Cancer 7, 847 (2007).

19. Schuff, M. et al. FoxN3 is required for craniofacial and eye development of Xenopus laevis. Dev. Dyn. 236, 226-239 (2007).

20. Li, W. et al. The FOXN3-NEAT1-SIN3A repressor complex promotes progression of hormonally responsive breast cancer. J. Clin. Invest. 127, 3421-3440 (2017).

21. Pati, D., Keller, C., Groudine, M. \& Plon, S. E. Reconstitution of a MEC1independent checkpoint in yeast by expression of a novel human fork head cDNA. Mol. Cell. Biol. 17, 3037-3046 (1997).

22. Busygina, V., Kottemann, M. C., Scott, K. L., Plon, S. E. \& Bale, A. E. Multiple endocrine neoplasia type 1 interacts with forkhead transcription factor CHES1 in DNA damage response. Cancer Res. 66, 8397-8403 (2006).

23. Whitney, E. M., Ghaleb, A. M., Chen, X.\& Yang, V. W. Transcriptional profiling of the cell cycle checkpoint gene Krüppel-like factor 4 reveals a global inhibitory function in macromolecular biosynthesis. Gene. Expr. 13, 85-96 (2006).

24. Li, Q. et al. MicroRNA-574-5p was pivotal for TLR9 signaling enhanced tumor progression via down-regulating checkpoint suppressor 1 in human lung cancer. PLoS ONE 7, e48278 (2012).

25. Samaan, G. et al. Foxn3 is essential for craniofacial development in mice and a putative candidate involved in human congenital craniofacial defects. Biochem. Biophys. Res. Commun. 400, 60-65 (2010).

26. Scott, K. L. \& Plon, S. E. CHES1/FOXN3 interacts with Ski-interacting protein and acts as a transcriptional repressor. Gene 359, 119-126 (2005).

27. Dai, Y. et al. Loss of FOXN3 in colon cancer activates beta-catenin/TCF signaling and promotes the growth and migration of cancer cells. Oncotarget $\mathbf{8}$, 9783 (2017).

28. Chang, J. T. et al. Identification of differentially expressed genes in oral squamous cell carcinoma (OSCC): overexpression of NPM, CDK1 and NDRG1 and underexpression of CHES1. Int. J. Cancer 114, 942-949 (2005).

29. Ying, $H$. et al. Retracted article: Risk miRNA screening of ovarian cancer based on miRNA functional synergistic network. J. Ovarian Res. 7, 226 (2014).

30. Mudduluru, G. et al. A systematic approach to defining the microRNA landscape in metastasis. Cancer Res. 75, 3010-3019 (2015).

31. Robertson, E., Perry, C., Doherty, R. \& Madhusudan, S. Transcriptomic profiling of Forkhead box transcription factors in adult glioblastoma multiforme. Cancer Genomics Proteomics 12, 103-112 (2015).

32. Sun, J. et al. The transcription factor FOXN3 inhibits cell proliferation by downregulating E2F5 expression in hepatocellular carcinoma cells. Oncotarget 7, 43534 (2016).

33. Huot, G. et al. CHES1/FOXN3 regulates cell proliferation by repressing PIM2 and protein biosynthesis. Mol. Biol. Cell. 25, 554-565 (2014).

34. Karanth, S., Zinkhan, E. K., Hill, J. T., Yost, H. J. \& Schlegel, A. FOXN3 regulates hepatic glucose utilization. Cell Rep. 15, 2745-2755 (2016).

35. Carroll, J. S. et al. Chromosome-wide mapping of estrogen receptor binding reveals long-range regulation requiring the forkhead protein FoxA1. Cell 122 33 (2005).

36. Zou, Y. et al. Forkhead box transcription factor FOXO3a suppresses estrogendependent breast cancer cell proliferation and tumorigenesis. Breast Cancer Res. 10, R21 (2008).
37. Liu, Y. et al. FOXK2 transcription factor suppresses ERa-positive breast cancer cell growth through down-regulating the stability of ERa via mechanism involving BRCA1/BARD1. Sci. Rep. 5, 8796 (2015).

38. Shan, L. et al. FOXK2 elicits massive transcription repression and suppresses the hypoxic response and breast cancer carcinogenesis. Cancer Cell. 30, 708 (2016).

39. Ao, X. et al. Sumoylation of TCF21 downregulates the transcriptional activity of estrogen receptor-alpha. Oncotarget 7, 26220 (2016).

40. Xiao, L. et al. Induction of the CLOCK gene by E2-ERa signaling promotes the proliferation of breast cancer cells. PLoS ONE 9, e95878 (2014).

41. Glozak, M. A., Sengupta, N., Zhang, X. \& Seto, E. Acetylation and deacetylation of non-histone proteins. Gene 363, 15-23 (2005).

42. Spange, S., Wagner, T., Heinzel, T. \& Krämer, O. H. Acetylation of non-histone proteins modulates cellular signalling at multiple levels. Int. J. Biochem. Cell. Biol. 41, 185-198 (2009)

43. Rieber, M. \& Strasberg-Rieber, M. p53 inactivation decreases dependence on estrogen/ERK signalling for proliferation but promotes EMT and susceptility to 3-bromopyruvate in ERa+ breast cancer MCF-7 cells. Biochem. Pharmacol. 88 169-177 (2014).

44. Asem, M. S., Steven, B., Burkhalter, W. R., Miller, D. L. \& Sharon, S. M. Wnt5a signaling in cancer. Cancers 8, 79 (2016).

45. Scott, K. L. \& Plon, S. E. Loss of Sin3/Rpd3 histone deacetylase restores the DNA damage response in checkpoint-deficient strains of Saccharomyces cerevisiae. Mol. Cell. Biol. 23, 4522 (2003).

46. Ota, H. et al. Sirt1 inhibitor, Sirtinol, induces senescence-like growth arrest with attenuated Ras-MAPK signaling in human cancer cells. Oncogene 25, 176-185 (2006).

47. Stender, J. D. et al. Estrogen-regulated gene networks in human breast cancer cells: involvement of E2F1 in the regulation of cell proliferation. Mol. Endocrinol. 21, 2112-2123 (2007)

48. Tang, Z. et al. GEPIA: a web server for cancer and normal gene expression profiling and interactive analyses. Nucleic Acids Res. 45 W98-W102 (2017)

49. Györffy, B. et al. An online survival analysis tool to rapidly assess the effect of 22,277 genes on breast cancer prognosis using microarray data of 1,809 patients. Breast Cancer Res. Treat. 123, 725-731 (2010).

50. Shuaiying Cui, K. E. K. et al. . Nuclear receptors TR2 and TR4 recruit multiple epigenetic transcriptional corepressors that associate specifically with the embryonic $\beta$-type globin promoters in differentiated adult erythroid cells. Mol. Cell. Biol. 31, 3298-3311 (2011).

51. Robinson, D. R. et al. Integrative clinical genomics of metastatic cancer. Nature 548, 297 (2017)

52. Kasai, H., Allen, J. T., Mason, R. M., Kamimura, T. \& Zhang, Z. TGF- $\beta 1$ induces human alveolar epithelial to mesenchymal cell transition (EMT). Respir. Res. $\mathbf{6}$, 56 (2005).

53. Moses, H. L., Yang, E. Y. \& Pietenpol, J. A. TGF- $\beta$ stimulation and inhibition of cell proliferation: New mechanistic insights. Cell 63, 245-247 (1990).

54. $\mathrm{Xu}$, J. et al. 14-3-3 turns TGF-ß3's function from tumor suppressor to metastasis promoter in breast cancer by contextual changes of Smad partners from p53 to Gli2. Cancer Cell. 27, 177 (2015).

55. Li, S. et al. CLOCK is a substrate of SUMO and sumoylation of CLOCK upregulates the transcriptional activity of estrogen receptor-a. Oncogene $\mathbf{3 2}$ 4883-4891 (2013)

56. Li, S. et al. SUMOylation of PES1 upregulates its stability and function via inhibiting its ubiquitination. Oncotarget 7, 50522 (2016).

57. $\mathrm{Bi}, \mathrm{H}$. et al. $\mathrm{DEC} 1$ regulates breast cancer cell proliferation by stabilizing cyclin $\mathrm{E}$ protein and delays the progression of cell cycle S phase. Cell Death Dis. 6 , e1891 (2015).

58. Zhao, F. et al. DACH1 inhibits SNAl1-mediated epithelial-mesenchymal transition and represses breast carcinoma metastasis. Oncogenesis 4, e143 (2015). 